This is the last draft sent to the Editorial by the authors of the article:

M. GÓMEZ, L. RANCEL, S.F. MEDINA

"Effects of aluminium and nitrogen on static recrystallisation in Vmicroalloyed steels"

Materials Science and Engineering A

Vol. 506 (2009), Pages: 165-173

DOI: 10.1016/j.msea.2008.11.049

ISSN: 0921-5093

To be published in Digital.CSIC, the Institutional Repository of the Spanish National Research Council (CSIC)

See more papers from the authors on:

$\underline{\text { http://digital.csic.es }}$

http://www.researcherid.com/rid/B-7922-2008 


\title{
Effects of aluminium and nitrogen on static recrystallisation in $\mathrm{V}$ - microalloyed steels
}

\author{
M. Gómez, L. Rancel and S.F. Medina \\ National Centre for Metallurgical Research (CENIM-CSIC), Av. Gregorio del Amo 8; \\ 28040-Madrid, Spain \\ mgomez@cenim.csic.es, $\underline{\text { smedina@cenim.csic.es, }}$
}

\begin{abstract}
:
Static recrystallisation of three steels having different $\mathrm{Al}, \mathrm{V}$ and $\mathrm{N}$ contents (one of them without V) has been studied by means of hot torsion tests. It has been found that straininduced precipitates of AlN in the austenite have a mean size of approximately $86 \mathrm{~nm}$. These particles barely inhibit the static recrystallisation, as associated pinning forces are very weak. However, mean size of VCN particles is equal to $11 \mathrm{~nm}$. This fine size leads to a temporary inhibition of recrystallisation, revealed by the characteristic "plateau" of the plots of recrystallised fraction versus holding time after deformation. Besides, activation energy for recrystallisation considerably augments when VCN precipitation occurs, but it hardly increases when AlN particles precipitate. On the other hand, diffusion coefficient of $\mathrm{Al}$ in austenite is two orders of magnitude higher than for V. Furthermore, according to thermodynamic calculations based on Hillert and Staffanson method, precipitation of AlN particles starts at much higher temperatures than VCN. Aforesaid reasons make AIN particles to be much coarser than VCN precipitates. From the results it can be concluded that low Al contents would lead to more intense precipitation of $\mathrm{VCN}$, that is beneficial for $\mathrm{V}$-microalloyed steels.
\end{abstract}

Keywords: strain induced precipitation, particle growth, diffusion in austenite, static recrystallisation, RPTT diagram.

\section{Introduction}

The type and amount of microalloying elements play an important role on the shape and the nature of precipitates. However, the impact of some elements that are not considered as authentic microalloying elements is usually underestimated, even though the influence of these elements on chemical composition, size and distribution of precipitates can be even stronger than that of microalloying. This is true for aluminium-killed, V-microalloyed steels, whose Al contents are often higher than 0.020 mass $\%$. This amount can promote the precipitation of aluminium nitrides instead of vanadium nitrides. VN particles are finer than AlN and therefore they have a stronger contribution during hot rolling. Fine VN precipitates inhibit static recrystallisation of austenite, which leads to austenite strengthening during last hot rolling passes. Besides, VN promotes intragranular nucleation of ferrite. At equal level of $\mathrm{Al}$ or $\mathrm{V}$ alloying, AlN precipitates are less soluble in austenite than VN particles [1,2], i.e. solubility temperature of AlN is higher than that of VN. On the 
other hand the presence of AlN in the austenite generates harmful effects on the hotductility of different kinds of steels $[3,4]$.

Crystallographic structure of AlN is hexagonal (h.c.p.), but AlN can occasionally form complex precipitates with cubic (f.c.c.) structure when the steel contains other elements with a high affinity for nitrogen, such as $\mathrm{Ti}$ and $\mathrm{Nb}$ [5-7]. Nitrides and carbides of typical microalloying elements $(\mathrm{Nb}, \mathrm{V}, \mathrm{Ti})$ have an f.c.c. crystallographic structure. These compounds, especially in the case of the smallest particles, frequently form precipitates which are semi-coherent with the austenitic (f.c.c) matrix. Lattice parameter is slightly higher than that of the austenite [8]. VCN particles have low interfacial energy with respect to ferrite but relatively high interfacial energy with respect to austenite for the $(001) \mathrm{V}(\mathrm{C}, \mathrm{N})$ boundary compared with MnS. Such advantages of VC and VCN over MnS in the balance of interphase boundary energy presumably promote the intragranular ferrite transformation [9].

In this work static recrystallisation of austenite is studied in three steels with different $\mathrm{V}$ and $\mathrm{N}$ contents. The influence of $\mathrm{VCN}$ and $\mathrm{AlN}$ precipitates is studied and the convenience of restricting the $\mathrm{Al}$ content in $\mathrm{V}$-microalloyed steels is established.

\section{Materials and experimental procedure}

The steels, whose chemical compositions are shown in Table 1, were industrially manufactured. They are two low-carbon V-microalloyed structural steels and another lowcarbon Al-steel.

$\mathrm{Al}$ contents in the three steels are roughly similar. However, whereas $\mathrm{Al} / \mathrm{N}$ ratio is similar in steels $\mathrm{Y} 7$ and $\mathrm{Y} 9$ and it is lower than the stoichiometric ratio of AlN (1.93), steel X3 presents a higher $\mathrm{Al} / \mathrm{N}$ ratio. On the other hand, $\mathrm{V}$ and $\mathrm{N}$ contents are different for each steel. V/N ratio is equal to zero in steel $\mathrm{Y} 7$, lower than VCN stoichiometric ratio (3.64) in steel Y9 and much higher in steel X3.

The specimens for torsion testing had a gauge length of $50 \mathrm{~mm}$ and a diameter of $6 \mathrm{~mm}$. According to Hillert and Staffanson's model [10], the austenitisation temperature was set to be higher than the solubility temperature of $\mathrm{VCN}$, thus assuring that the precipitates would be completely dissolved in the austenite. Therefore the torsion samples were austenitised at $1200^{\circ} \mathrm{C}$ during 10 minutes. Only for the steel Y7, a different austenisation temperature of $1300^{\circ} \mathrm{C}$ was applied in order to put AlN precipitates into solution. After quenching the specimen in water and carrying out the subsequent metallographic study, the mean austenite grain size corresponding to the austenitisation conditions was determined for each steel by applying ASTM E-112 standard (Table 2). The three steels had the same austenite grain size of $151 \mu \mathrm{m}$ for the austenitisation temperature of $1200^{\circ} \mathrm{C}$. Steel $\mathrm{Y} 7$ (the one without vanadium) presented a grain size at $1300^{\circ} \mathrm{C}$ equal to $550 \mu \mathrm{m}$, so it suffered a noteworthy grain coarsening compared to reheating at $1200^{\circ} \mathrm{C}$.

After austenitisation, the specimens were rapidly cooled to the deformation temperature in order to prevent precipitation prior to deformation. The deformation temperatures were 
between $1100^{\circ} \mathrm{C}$ and $800^{\circ} \mathrm{C}$, and the recrystallised fraction $\left(\mathrm{X}_{\mathrm{a}}\right)$ was determined for several holding times after deformation. The applied strains were 0.20 and 0.35 , which were insufficient to promote dynamic recrystallisation [11].

The double deformation technique was used to calculate $\mathrm{X}_{\mathrm{a}}$, in particular applying the method known as back extrapolation. The advantage of the latter is that while the simple method of double deformation allows the softened fraction to be calculated as the sum of the recovered fraction plus the recrystallised fraction, the back extrapolation variant allows the determination of just the recrystallised fraction or an approximation to this $[12,13]$.

Microstructures of the transformed specimens were examined by means of optical and transmission electron microscopy (TEM). For optical observations, specimens were etched with $2 \%$ nital. Carbon extraction replicas were used for precipitate analysis by TEM. Electron probe microanalyser (EPMA) and TEM-EDS (energy dispersive X-ray spectroscopy) analyses were made for identifying precipitate phases.

\section{Static recrystallisation model}

The static recrystallisation kinetics of austenite can be described by an Avrami equation in the following way [14]:

$$
X_{a}=1-\exp \left[-0.693\left(\frac{t}{t_{0.5}}\right)^{n}\right] \ldots \ldots \ldots \ldots \ldots \ldots \ldots \ldots \ldots \ldots \ldots \ldots
$$

where $X_{a}$ is the fraction of the recrystallised volume and $t_{0.5}$ is the time corresponding $50 \%$ recrystallisation, which depends practically on all the variables that intervene in hot deformation and whose most general expression can be expressed by the equation:

$$
t_{0.5}=A \varepsilon^{p} \dot{\varepsilon}^{q} D^{s} \exp \frac{Q_{x}}{R T}
$$

where $\varepsilon$ is the strain, $\dot{\varepsilon}$ the strain rate, $\mathrm{D}$ the grain size, $\mathrm{Q}_{\mathrm{x}}$ the activation energy, $\mathrm{T}$ the absolute temperature, $\mathrm{R}=8.3145 \mathrm{Jmol}^{-1} \mathrm{~K}^{-1}$, and $p, q$ and $s$ are parameters. While $p$ and $q$ are negative values, $s$ is positive.

The activation energy $\left(Q_{\mathrm{x}}\right)$ for the static recrystallisation of austenite represents to a good extent the grain boundary self-diffusion energy and is affected both by solute drag and also by the presence of precipitates [15-18].

The variation in activation energy as a function of the chemical composition has showed that solute atoms interact with the grain boundaries. If the sizes of the solute and matrix atoms are different, then there will be an elastic stress field introduced into the lattice by each foreign atom. The elements that most distort the lattice structure of austenite have the largest effect on 
grain boundary migration. The greater the atomic volume of the substitutional elements, the greater the distortion [19].

The activation energy $\left(Q_{x}\right)$ for the static recrystallisation of austenite with the presence of precipitates may be expressed as the sum of two terms:

$$
Q_{x}=Q+\Delta Q
$$

where $Q$ represents the activation energy in the absence of precipitates and $\Delta Q_{p}$ represents the increase due to the presence of the precipitates. Precipitates in austenite produce a delaying effect on recrystallisation kinetics, due to the fact that the pinning forces -which try to prevent grain boundary self-diffusion- increase considerably.

Several models that predict the static recrystallisation kinetics by taking into account the chemical composition and kind of precipitates have been reported [15-18]. These expressions are shown in Appendix and let to compare the influence exerted by the most common alloying and microalloying elements in solution as well as the different types of precipitates on static recrystallisation kinetics, and particularly on activation energy.

On the other hand, when the recrystallised fraction of a $\mathrm{V}$ or $\mathrm{Nb}$ microalloyed steel is plotted against the natural logarithm of time, the curves corresponding to temperatures where the microalloying elements are still in solution have the typical sigmoidal shape as suggested by the Avrami's law. However, the curves corresponding to temperatures where strain-induced precipitation has taken place present a plateau. This plateau indicates that the recrystallised fraction is temporarily inhibited until it starts to progress again, also following Avrami's law [20]. A model predicting the formation of the plateau has been reported by Zurob at al. [21].

The start and the end of the plateau have been found to corresponding to the start and end of strain-induced precipitation. However, while the start of the plateau seems to coincide with good exactness with the start of strain-induced precipitation [22,23], the end of the plateau could coincide with an important growth in the average size of precipitates, which become incapable of inhibiting recrystallisation [22] or that, despite the fact that the average size has grown, there is still a certain volume of small size precipitates uniformly distributed in the austenite matrix [23]. Though the two definitions might at first sight seem different, in fact they mean practically the same thing.

\section{Results and discussion}

\subsection{Recrystallised fraction}

The shape of the recrystallised fraction against time curves were similar for the two Vmicroalloyed steels, i.e. the curves presented a plateau when the temperature was below the static recrystallisation critical temperature (SRCT). This is the temperature at which recrystallisation starts to be inhibited owing to the effect of strain-induced precipitation [24]. 
Fig. 1 shows the recrystallised fraction for steel X3 at a strain of 0.20 , strain rate of $3.63 \mathrm{~s}^{-1}$ and several temperatures, with a plateau appearing on the curve corresponding at $900^{\circ} \mathrm{C}$ and $850^{\circ} \mathrm{C}$. Fig. 2 presents the recrystallised fraction kinetics for a strain equal to 0.35 also showing the plateau in both curves. A comparison of Fig. 1 and 2 lets to verify that, at given strain, temperature and holding time, recrystallised fraction increases with deformation, as predicted by Equation (2), where exponent $p$ is negative (see Appendix).

Steel Y9 exhibits a similar performance to steel X3. The curves of recrystallised fraction against time (Figs. 3 and 4) show a sigmoidal shape when precipitates are in solution in the austenite, whereas a plateau is displayed when strain-induced precipitation is assumed to occur.

Regarding the steel without vanadium (Y7), recrystallised fraction (Fig. 5) was only determined for the higher strain value $(\varepsilon=0.35)$, as this steel presents a similar behaviour to a C-Mn steel, i.e. an extended plateau like that found in $\mathrm{Nb}$ - and V-microalloyed steels $[15,16]$ cannot be seen. A very short plateau can be distinguished only for the temperatures of $1000^{\circ} \mathrm{C}$ and $900^{\circ} \mathrm{C}$. Recrystallisation curves could have been assimilated to a sigmoidal regression, but previous studies carried out on steels where Al was the sole alloying element have confirmed that a small plateau -like that displayed in present study- appears as a result of AlN precipitation [25]. As reheating temperature $\left(1200^{\circ} \mathrm{C}\right)$ was somewhat lower than solubility temperature of AlN precipitates in steel Y7, additional tests with a reheating treatment of $1300^{\circ} \mathrm{Cx} 10$ min were done on samples of steel Y7. Doing so, the complete dissolution of AIN particles in austenite matrix was assured. Recrystallised fraction was now determined at $1000^{\circ} \mathrm{C}$ and using strain values of 0.20 and 0.35 (Fig. 6). The plot corresponding to $\varepsilon=0.35$ shows a higher recrystallised fraction, which agrees with equation (2). On the other hand, when the curve corresponding to $\varepsilon=0.35$ is compared to the curve of $1000^{\circ} \mathrm{C}$ in Fig. 5 , it can be seen that the first plateau is slightly wider, although it is still shorter than the plateaus of steels X3 and Y9. Therefore, it is seen that complete dissolution of AlN precipitates at $1300^{\circ} \mathrm{C}$ leads to some increase in the strain-induced precipitated volume.

\subsection{RPTT diagrams}

Figures showing the recrystallised fraction versus time were used to deduce the temperature and times corresponding to different recrystallised fractions, such $0.3,0.5,0.7$ and 0.9 . The points that define the start and the end of the plateau were taken to plot the induced precipitation start $\left(\mathrm{P}_{\mathrm{s}}\right)$ and finish $\left(\mathrm{P}_{\mathrm{f}}\right)$ curves, respectively. In this way recrystallisationprecipitation-time-temperature (RPTT) diagrams for the studied steels were drawn (Figs. 711). Note that the recrystallisation inhibition kinetics is given by the period between the precipitation start curve $\left(\mathrm{P}_{\mathrm{s}}\right)$ and the finish curve $\left(\mathrm{P}_{\mathrm{f}}\right)$.

The recrystallised fraction does not vary between the precipitation start $\left(\mathrm{P}_{\mathrm{s}}\right)$ and finish $\left(\mathrm{P}_{\mathrm{f}}\right)$ curves and is represented by a horizontal line. Once the $\mathrm{P}_{\mathrm{f}}$ curve is reached, the lines of each recrystallised fraction descend again. 
The V-steels show a longer precipitation period than the Al-steels indicating that the VCN precipitates should be smaller than AIN precipitates, so the pinning forces are greater in the first case than in the second.

The most important magnitudes that can be deduced from a RPTT diagram, and which are also indispensable for the perfect configuration of the diagram, are the minimum incubation time $\left(t_{N}\right)$, the minimum time for precipitation to finish $\left(t^{\prime}{ }_{N}\right)$, the curve nose temperature $\left(T_{N}\right)$ and the duration time of precipitation $\left(\mathrm{t}^{\prime}{ }_{\mathrm{N}}^{-} \mathrm{t}_{\mathrm{N}}\right)[24]$.

The values of the minimum incubation time $\left(t_{N}\right)$ and the curve nose temperature $\left(T_{N}\right)$ are shown in Table 3 for the steels studied. The value of $t_{N}$ decreases as the strain increases and the $\mathrm{V}$ content also increases. On the other hand, comparison of RPTT diagrams shows that AlN particles nucleate earlier and grow faster than VCN particles. The results are striking, as $t_{N}=7 \mathrm{~s}$ for steel Y7, being an order of magnitude shorter than steels X3 and Y9.

At the instant that precipitation starts, which coincides approximately with the $\mathrm{P}_{\mathrm{s}}$ curve, at any deformation temperature, the precipitated volume percentage is assumed to be less than or close to $5 \%$. When the $\mathrm{P}_{\mathrm{f}}$ curve is reached it is assumed that precipitation has ended, although this is not yet sufficiently demonstrated. It is known that at the end of plateau, recrystallisation starts to proceed, and therefore the pinning forces must be lower than the driving forces for recrystallisation. However, recent studies have shown that at the end of the plateau a small fraction of precipitates conserve the same size as the precipitates formed at the start of precipitation. Therefore, this suggests that the end of the plateau, or the $\mathrm{P}_{\mathrm{f}}$ curve, coincides only roughly with the end of precipitation [26]. The RPTT diagrams, and especially the $\mathrm{P}_{\mathrm{s}}$ and $\mathrm{P}_{\mathrm{f}}$ curves, define a time interval, whatever the temperature, during which the precipitation state (size and precipitated volume) is changing.

With regard to the recrystallisation-precipitation interaction, it is seen that the nose of the $\mathrm{P}_{\mathrm{s}}$ curve, where the incubation time of the precipitates $\left(t_{\mathrm{N}}\right)$ is shortest, the recrystallised fraction is approximately $50 \%$. When the fraction of recrystallised volume is less than $20 \%$, nucleation of the precipitates needs longer time to take place.

\subsection{Activation energy}

The activation energy can be easily determined from recrystallised fraction against time curves or from RPTT diagrams. In accordance with Eq. (2), Figs. 11-13 display the parameter $t_{0.5}$ against the inverse of the absolute temperature for steels X3, Y9 at two strains of 0.20 and 0.35 , and $Y 7$ at strain of 0.35 .

The line $\ln t_{0.5}$ against $1 / T$ shows a discontinuity just when the temperature reaches the nose of RPTT diagram. The jump between stages takes place in a time interval that coincides with the interval $\mathrm{P}_{\mathrm{f}}-\mathrm{P}_{\mathrm{s}}$ close to the nose of the $\mathrm{P}_{\mathrm{s}}$ curves. The slope of each line multiplied by the universal gas constant $(\mathrm{R})$ gives the activation energy before $(\mathrm{Q})$ and after precipitation (Q'). In other words, the value of the activation energy changes from one stage to another and this occurs at a constant temperature during the time that precipitation takes place $\left(\mathrm{P}_{\mathrm{f}}-\mathrm{P}_{\mathrm{s}}\right)$. After precipitation the activation energy increases significantly, which is obviously translated into greater difficulty for the austenite to recrystallise. Each figure shows the values of Q and Q' 
for the steels studied. Activation energy does not depend on strain and the indicated values represent the calculated average for the two strains. The differences between Q' and Q represents the increment in activation energy due to the presence of precipitates $(\Delta Q)$.

The comparison of the values shown in Table 4 demonstrates that the contribution of precipitates to the increment in activation energy $(\Delta Q)$ is much higher for VCN precipitates than for AlN particles. This explains the different effects that both types of precipitates exert on static recrystallisation of austenite.

\subsection{Thermodynamic study of precipitation}

Hillert and Staffanson's model [10] permits the prediction of the formation of simple precipitates (nitrides and carbides) and more complex precipitates (carbonitrides) and the results can be expressed as a fraction of the precipitated volume versus temperature. Fig. 15 shows that the model predicts the formation of AIN and VCN in steels X3 e Y9 and AIN in steel Y7, also noting the temperatures at which the precipitates start to dissolve. These results are thermodynamic predictions and should not be interpreted as the real results obtained in steels X3 and Y9 at tested deformation temperatures. Deformation has been applied after undercooling and precipitation has been induced by strain, so it arises at very short times as RPTT diagrams indicate. However, the calculations are important in showing that under equilibrium conditions, precipitated volume of $\mathrm{AlN}$ is higher in steel X3 than in steel Y9. Besides, precipitated volume of $\mathrm{VCN}$ in steel $\mathrm{X} 3$ is higher than the volume of $\mathrm{AlN}$ at temperatures below $850^{\circ} \mathrm{C}$, but it is lower at higher temperatures. In steel $\mathrm{Y} 9$, precipitated volumes of $\mathrm{AIN}$ and $\mathrm{VCN}$ are similar until $800^{\circ} \mathrm{C}$. For higher temperatures, volume of AIN starts to be much more important. In both steels, VCN dissolves before AIN until a temperature of $1100^{\circ} \mathrm{C}$ is reached, where the latter is also practically in solution.

Precipitated volume fraction of $\mathrm{VCN}$ is substantial (i.e. higher than $10^{-4}$ ) for temperatures lower than $900{ }^{\circ} \mathrm{C}$ in steel $\mathrm{X} 3$ and $950^{\circ} \mathrm{C}$ in steel $\mathrm{Y} 9$, but it steeply decreases at higher temperatures.

The relationship between precipitated volume fractions and the formation of the plateau is evident, since steel $\mathrm{X} 3$ presents a plateau at $900^{\circ} \mathrm{C}$ and below, whereas in steel $\mathrm{Y} 9$ the plateau is displayed at temperatures equal to or lower than $950^{\circ} \mathrm{C}$.

\subsection{Analysis by TEM of precipitates}

In order to know the type and size of the precipitates, a study was carried out, using transmission electron microscopy (TEM), with steel Y9 in continuous cooling conditions. Prior to the simulation test the specimens were reheated at a temperature of $1200^{\circ} \mathrm{C}$ for 10 min. The temperature was then lowered to that corresponding to the first pass, which was $1175^{\circ} \mathrm{C}$. The simulations consisted of the performance of 21 passes, with a temperature step of $25^{\circ} \mathrm{C}$ between passes, the last pass being carried out at $675^{\circ} \mathrm{C}$. The strain applied in each pass was of 0.20 and 0.35 , and the strain rate was equal to $3.63 \mathrm{~s}^{-1}$. Several interpass times $(\Delta \mathrm{t})$ ranging from 20 to $200 \mathrm{~s}$ were used. All the values of no recrystallisation temperature 
$\left(T_{n r}\right)$ and phase transformation $\left(A_{r 3}\right)$ were measured by using the graphs of MFS versus $1 / T$ (Fig. 16).

The analysis of precipitates was performed carrying out a similar schedule to the rolling simulation of Fig. 16, performed with a pass strain of 0.35 and interpass time of $60 \mathrm{~s}$, but final pass was accomplished at $800^{\circ} \mathrm{C}$, above the temperature $\mathrm{Ar} 3$, and the sample was subsequently cooled. This cooling is showed in Fig. 16 by an arrow. Two types of precipitates were observed. On the one hand, fine VCN precipitates, as shown in Fig. 17-a, and a great amount of large AIN precipitates (Fig. 17-b). The lattice parameter determined revealed an f.c.c. cubic lattice with a value of $0.412 \mathrm{~nm}$ for the $\mathrm{VCN}$ and h.c.p. lattice for AlN with parameter values of $0.312 \mathrm{~nm}$ and $0.497 \mathrm{~nm}$.

Sizes of more than $300 \mathrm{VCN}$ and 300 AlN particles were measured. Figs. 18 and 19 show the size distribution for both types of precipitates. Mean size of VCN and AIN particles was respectively equal to $11.2 \mathrm{~nm}$ and $86.2 \mathrm{~nm}$, so the latter is almost one order of magnitude bigger than the former.

\subsection{Pinning and driving forces for recrystallisation}

The pinning forces opposing grain growth and the progress of recrystallisation were determined. The pinning force exerted by a number of particles per unit of area $\left(\mathrm{N}_{\mathrm{s}}\right)$ on the grain boundary is given by [12]:

$F_{p}=\pi r \gamma N_{s}$

where $\gamma$ is the interfacial energy per unit of area $\left(0.8 \mathrm{~J} / \mathrm{m}^{2}\right)$ and $r$ is the average radius of the second phase particles.

For the calculation of pinning forces consideration was made of the expressions of Gladman, rigid boundary and flexible boundary models, respectively, which are differentiated in the way of calculating $\mathrm{N}_{\mathrm{s}}[8,27,28]$ :

a) Gladman expression:

$F_{p}=\frac{3 f \gamma}{2 r} \ldots \ldots \ldots \ldots \ldots$

b) Rigid boundary model:

$F_{p}=6 \gamma f / \pi r$

c) Flexible boundary model:

$F_{p}=3 \gamma f^{2 / 3} / \pi r$

The values of precipitated volume fraction $(f)$ for $\mathrm{VCN}$ and AlN particles corresponding to $800{ }^{\circ} \mathrm{C}$ (temperature from which the sample was cooled) are deducted from Fig. 15. The 
values of average radius $r$ are found in Fig. 18 and Fig. 19. The results show that the rigid boundary model yielded pinning forces similar as those calculated in accordance with Gladman, and pinning forces exerted by AlN particles are approximately one order of magnitude weaker than those caused by VCN precipitates (Table 5).

The driving forces for recrystallisation were calculated for the four steels and all the deformation conditions using the following expression [21]:

$$
\mathrm{F}_{\mathrm{r}}=\mu \mathrm{b}^{2} \Delta \mathrm{p} / 2
$$

where $\mu$ is the shear modulus, $\left(4 \times 10^{4} \mathrm{MN} / \mathrm{m}^{2}\right), \mathrm{b}$ is Burger's vector $\left(2 \times 10^{-10} \mathrm{~m}\right)$ and $\Delta \mathrm{p}$ is the variation in the density of dislocations associated with the movement of the recrystallisation front in the deformed zone. Although this equation does not directly reflect the influence of the temperature, its influence is contemplated in $\Delta \mathrm{p}$.

On the other hand, the value of $\Delta \mathrm{p}$ during hot working is related with the increase in flow stress [29]:

$$
\sigma_{m}=0.2 \mu b \sqrt{\Delta p}
$$

where $\sigma_{m}$ is the MFS reached in the flow curve for each pass.

The driving forces for recrystallisation $\left(\mathrm{F}_{\mathrm{r}}\right)$ were calculated for steel Y9 according to the above expressions from MFS curve. Fig. 20 show $F_{r}$ calculated in each pass in accordance with equations 8 and 9, versus the pass reciprocal temperature. As the temperature decreases, the driving forces increase as a consequence of the rise in the stress and thus in the density of dislocations. In all cases, $\mathrm{F}_{\mathrm{r}}$ has been represented up to $800^{\circ} \mathrm{C}$.

The values reached for $F_{r}$ in all cases exceed the pinning forces by more than an order of magnitude, which demonstrates that in these steels, where the precipitation is straininduced, recrystallisation always progresses when the interpass time is long enough to complete it. In other words, the comparison between pinning and driving forces shows that interpass recrystallisation is thermodynamically possible, although from the point of view of kinetics, the fraction of interpass recrystallisation would depend on the variables that affect it, such as the interpass time, temperature, strain in each pass, and strain rate.

\subsection{Precipitate growth}

Fig. 11 shows that the size of AlN precipitates grows quickly, and consequently the recrystallisation is inhibited only for some seconds. However, the growth of VCN particles is slower, as shown in Figs. 7-10. It has been seen in previous section that the sizes of precipitates are very different and AIN particles are almost one order of magnitude coarser than VCN. The particle diameter at any temperature can be expressed as [30,31]:

$$
\Delta d^{2}=\alpha^{2} D_{0} \exp \left(-\frac{Q_{d}}{R T}\right) \Delta t
$$


where $\Delta d^{2}=d^{2}-d_{0}^{2}$ and $\Delta t=t-t_{0}$. Here, $d_{0}$ is the particle diameter at time $t_{0 .} \alpha$ is the growth coefficient, $D_{0} \exp \left(-\frac{Q_{d}}{R T}\right)$ is the diffusion coefficient (D) of $\mathrm{Al}, \mathrm{V}$ and $\mathrm{N}$ in austenite.

Equation (10) can be applied to predict the growth of precipitates that nucleate during cooling. The number of available sites for the nucleation per unit volume, is the number of nodes in the dislocation network and is given as [32]:

$N_{0}=0.5 \rho^{1.5}$

Where, $\rho$ is the dislocation density at the beginning of precipitation. This value can be calculated in every simulated rolling pass according to Equation (9) and MFS values represented in Fig. 18. Nevertheless, the number of potential sites for nucleation would be the same for both types of particles, AlN and VCN. Consequently, the difference in sizes between particles should be found in the factors influencing particle growth, i.e. coefficients $\alpha$ and D. Coefficient $\alpha$ of AlN and VCN is given by an expression that respectively considers the $\mathrm{Al}$ or $\mathrm{V}$ contents (weight \%) in the particle, the matrix and the interphase [33]. The value of this coefficient does not greatly differ between both types of particles.

Regarding coefficient $\mathrm{D}$, the expressions proposed for both types of precipitates are the following [34-36]:

$$
\begin{aligned}
& D_{A l}=5.9 \exp \left(-\frac{241000}{R T}\right) \ldots \ldots \ldots \ldots \ldots \ldots . .(12) \\
& D_{V}=0.28 \exp \left(-\frac{264000}{R T}\right) \ldots \ldots \ldots \ldots \ldots \ldots(13) \\
& D_{N}=4.88 \exp \left(-\frac{76780}{R T}\right) \ldots \ldots \ldots \ldots \ldots \ldots
\end{aligned}
$$

These expressions were calculated and graphically represented against the inverse of absolute temperature (Fig. 21). The diffusion coefficient for $\mathrm{Al}$ is two orders of magnitude larger than for $\mathrm{V}$. Besides, AlN particles start to precipitate at temperatures close to $1100^{\circ} \mathrm{C}$, while $\mathrm{VCN}$ precipitation starts at much lower temperatures, near $950^{\circ} \mathrm{C}$ (Fig. 15). This brings about an even more pronounced difference in parameter $\mathrm{D}$ in the first stages of precipitation. To sum up, the larger diffusion coefficient of $\mathrm{Al}$ compared to $\mathrm{V}$, together with the higher precipitation temperature of AlN temperatures serve to explain the coarser size of AlN particles.

Coarse AlN particles are inefficient to prevent recrystallisation and cause strengthening in the austenite. The harmful effect of coarse AlN particles has been shown by the authors in 
other studies about abnormal austenite grain growth [37]. On the other hand, AlN precipitates are not sources of intragranular nucleation of ferrite due to their large size and their incoherence with ferrite (high interfacial energy), whereas VCN particles are adequate for this phenomenon [25,38,39].

\section{Conclusions}

1. The mean size of strain-induced AlN precipitates is almost one order of magnitude bigger than the size of VCN particles.

2. The higher solubility temperatures of AlN along with the larger diffusion coefficient in austenite of $\mathrm{Al}$ compared to $\mathrm{V}$ are the main reasons of the coarser size of AlN particles.

3. The pinning forces exerted by coarse AlN precipitates are weak and accordingly the static recrystallisation of austenite is not inhibited by these particles.

4. The small increment of activation energy for austenite recrystallisation due to the presence of AlN, reveals the impossibility of austenite strengthening during hot rolling by the effect of AlN pinning particles.

5. Microalloyed steels, especially V-alloyed, should have a very low Al content. In this way, Al would not trap part of the $\mathrm{N}$ and the precipitated volume of VCN would be significantly higher. This would augment pinning forces and would contribute to a more intense strengthening of the austenite during rolling, thereby increasing the dislocation density and thereby the number of potential sites for the nucleation of ferrite.

\section{Acknowledgements}

Financial support of this work by the ECSC Project $7210-\mathrm{PR} / 289$ is gratefully acknowledged. 


\section{References}

[1] K. Narita, Trans. Iron Steel Inst. Jpn. 15 (1975) 145.

[2] E.T. Turkdogan, Iron Steelmaker 3 (1989) 61.

[3] B. Mintz, J.M. Arrowsmith, in: C.M Sellars and G.J. Davies (ed), Proc. Int. Conf. on Hot Working and Forming Processes, Metal Society, London, 1980, p. 99.

[4] G.D. Funnell, in: C.M Sellars and G.J. Davies (ed), Proc. Int. Conf. on Hot Working and Forming Processes, Metal Society, London, 1980, p 104.

[5] V. Massardier, V. Guétaz, J. Merlin, M. Soler, Mater. Sci. Eng. A, 355 (2003) 299.

[6] M. Sennour, C. Esnouf, Acta Mater. 51 (2003) 943.

[7] M. J. Leap, E. L. Brown, Scripta Mater. 47 (2002) 793.

[8] T. Gladman: The Physical Metallurgy of Microalloyed Steels, The Institute of Materials, London, 1997.

[9] T. Furuhara, J. Yamaguchi, N. Sugita, G. Miyamoto, T. Maki, ISIJ Int. 43 (2003) 1630.

[10] M. Hillert, L.I. Staffanson, Acta Chem. Scand. 24 (1970) 3618.

[11] S.F. Medina, C.A. Hernández, Acta Mater. 44 (1996) 149.

[12] H.L. Andrade, M.G. Akben, J.J. Jonas, Metall. Trans. A 14A (1993) 1967.

[13] J.S. Perttula, L.P. Karjalainem, Mater. Sci. Technol. 14 (1998) 626.

[14] J.H. Beynon, C.M. Sellars, ISIJ Int. 32 (1992) 359.

[15] S.F. Medina, J.E. Mancilla, ISIJ Int. 36 (1996), 1070.

[16] S.F. Medina, J.E. Mancilla, ISIJ Int. 36 (1996) 1077.

[17] S.F. Medina, A. Quispe, ISIJ Int. 41 (2001) 774.

[18] S.F. Medina, A. Quispe, M. Gómez, Mater. Sci. Technol. 19 (2003) 99.

[19] L.E. Toth, A.W. Searcy, Trans. Met. Soc. AIME 230 (1964) 690.

[20] A. Quispe, S.F. Medina, P. Valles, ISIJ Int. 37 (1997) 783.

[21] H. S. Zurob, Y. Brechet, G. Purdy, Acta Mater. 49 (2001) 4183.

[22] O. Kwon, A. DeArdo, Acta Metall. Mater. 39 (1990) 529.

[23] A. Quispe, S.F. Medina, J.M. Cabrera, J.M. Prado, Mater. Sci. Technol. 15 (1999) 635.

[24] S.F. Medina, A. Quispe, M. Gómez: Mater. Sci. Technol. 17 (2001) 536.

[25] S. Zajac, S.F. Medina, V. Schwinn, A. Osta, M. De Sanctis, G. Herman, Grain refinement by intragarnular ferrite nucleation on precipitates in microalloyed steels, European Communities, ISBN 92-79-04814-2; ISSN 1018-5593, Luxembourg 2007.

[26] S.F. Medina, A. Quispe, P. Valles, J.L. Baños, ISIJ Int. 39 (1999) 913.

[27] M. Gómez, S.F. Medina, P. Valles, ISIJ Int 45 (2005) 1711.

[28] M.I. Vega, S.F. Medina, A. Quispe, M. Gómez, P.P. Gómez, Mater. Sci. Eng. A 423 (2006) 253.

[29] A.S. Keh: Direct Observation of Imperfections in Crystals, Ed. by J.B. Newkirk and J.H. Wernick, Wiley-Interscience, New York, NY, (1962), 213.

[30] S.H. Park, S. Yue, J.J. Jonas, Metall. Trans A 23A (1992) 1641.

[31] S. Okaguchi, T. Hashimoto, ISIJ Int., 32 (1992) 283.

[32] B. Dutta, E. Valdes, C.M. Sellars, Acta Metall. Mater. 49 (2001) 785.

[33] Y. Kang, H. Yu, J. Fu, K. Wang, Z. Wang, Mater. Sci. Eng. A 351 (2003) 265. 
[34] A. Vignes, J. Philebert, J. Badía, J. Lavasseur, Proc. $2^{\text {nd }}$ Natl. Conf. Microprobe Analysis, Boston, 1967, Paper 20.

[35] J.D. Fast: Interaction of Metals and Gasses, London, Publ. Macmillan New York, (1976), p. 221.

[36] H. Oikawa: Tetsu-to-Hagane, 68 (1982)1489-1497.

[37] S. F. Medina, M. Chapa, Steel Research Int. 77 (2006) 712.

[38] S.F. Medina, M. Gómez, L. Rancel, Scripta Mater. 58 (2008) 1110.

[39] S.-X. Liu, Y. Chen, G.-Q. Liu, Y.-G. Zhang, J.-K. Huang, Mater. Sci. Eng. A 485 (2008) 492. 
APPENDIX: Static recristallisation model [16,17]:

$$
\begin{gathered}
X_{a}=1-\exp \left[-0.693\left(\frac{t}{t_{0.5}}\right)^{n}\right] \\
t_{0.5}=A \varepsilon^{p} \mathcal{E}^{q} D^{s} \exp \frac{Q_{x}}{R T}
\end{gathered}
$$

1. Microalloy elements are in solution:

$$
\begin{aligned}
Q\left(J^{m o l}{ }^{-1}\right)= & 148636.8-71981.3[\mathrm{C}]+56537.6[\mathrm{Si}]+21180[\mathrm{Mn}]+ \\
& +121243.3[\mathrm{Mo}]+64469.6[\mathrm{~V}]_{s}+109731.9[\mathrm{Nb}]_{s}^{0.15}
\end{aligned}
$$

where, each square bracket indicates the percentage by weight of the element indicated. For $\mathrm{V}$ and $\mathrm{Nb}$ the square bracket represent the percentage in solution.

$p=-4.3 D^{-0.17}$

$q=-0.505$

$s=1.09$

$A=3.754 \cdot 10^{-4} \exp \left(-7.869 \cdot 10^{-5} Q\right)$

All steels, except Nb-steels: $n=2.93 \exp \left(-\frac{12500}{R T}\right)$

Nb-steels: $n=28.33 \exp \left(-\frac{36000}{R T}\right)$

2. Microalloy elements are partial or completely precipitated

$t_{0.5}=A^{\prime} \varepsilon^{\left(-4.3 D^{-0.17}\right)} \dot{\mathcal{E}}^{-0.53} D \exp \left(\frac{Q^{\prime}}{R T}\right)$

$Q^{\prime}=Q+\Delta Q$ 
V-steels: $\quad \Delta Q(J)=1074 \cdot 10^{3}[V N]^{0.223} \ldots \ldots \ldots \ldots \ldots \ldots \ldots . . . .(A 10)$

Nb steels: $\quad \Delta Q(J)=1577 \cdot 10^{3}\left[N b C^{0.7} N^{0.2}\right]^{0.254} \ldots \ldots \ldots \ldots \ldots \ldots . . .(A 11)$

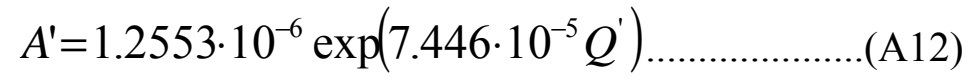


Table 1. Chemical composition of steel used $\left(\%\right.$ mass $\left.\times 10^{3}\right)$.

\begin{tabular}{|l|c|c|c|c|c|c|c|c|c|}
\hline Steel & $\mathrm{C}$ & $\mathrm{Mn}$ & $\mathrm{Si}$ & $\mathrm{Al}$ & $\mathrm{V}$ & $\mathrm{N}$ & $\mathrm{S}$ & $\mathrm{V} / \mathrm{N}$ & $\mathrm{A} 1 / \mathrm{N}$ \\
\hline $\mathrm{Y7}$ & 102 & 1479 & 284 & 20 & 0 & 15.8 & 4.8 & 0 & 1.27 \\
\hline $\mathrm{Y} 9$ & 102 & 1479 & 284 & 20 & 50 & 15.2 & 4.8 & 3.29 & 1.32 \\
\hline $\mathrm{X} 3$ & 94 & 1475 & 329 & 21 & 92 & 6.5 & 4.0 & 14.15 & 3.23 \\
\hline
\end{tabular}

Table 2. Austenite grain size $(d)$ for given reheating conditions.

\begin{tabular}{|c|c|c|}
\hline Steel & $\begin{array}{c}\text { Reheating } \\
\text { conditions }\end{array}$ & $(\bar{d}), \mu \mathrm{m}$ \\
\hline $\mathrm{X} 3$ & $1200^{\circ} \mathrm{Cx} 10 \mathrm{~min}$ & 151 \\
\hline $\mathrm{Y} 7$ & $1200^{\circ} \mathrm{Cx} 10 \mathrm{~min}$ & 151 \\
& $1300^{\circ} \mathrm{Cx} 10 \mathrm{~min}$ & 550 \\
\hline $\mathrm{Y} 9$ & $1200^{\circ} \mathrm{Cx} 10 \mathrm{~min}$ & 151 \\
\hline
\end{tabular}

Table 3. Temperature $T_{N}$; minimum incubation time $t_{N}$ of the $P_{s}$ curve nose; minimum finishing time ${ }^{\prime}{ }_{\mathrm{N}}$ of the $\mathrm{P}_{\mathrm{f}}$ curve nose and reheating temperature (RT).

\begin{tabular}{|c|c|c|c|c|c|c|}
\hline Steel & $\mathrm{RT},{ }^{\circ} \mathrm{C}$ & $\varepsilon$ & $\dot{\varepsilon}, \mathrm{s}^{-1}$ & $\mathrm{t}_{\mathrm{N},} \mathrm{s}$ & $\mathrm{t}^{\prime}{ }_{\mathrm{N}}, \mathrm{s}$ & $\mathrm{T}_{\mathrm{N}},{ }^{\circ} \mathrm{C}$ \\
\hline $\mathrm{X} 3$ & 1200 & 0.20 & 3.63 & 95 & 420 & 887 \\
\hline $\mathrm{X} 3$ & 1200 & 0.35 & 3.63 & 65 & 320 & 875 \\
\hline $\mathrm{Y} 7$ & 1200 & 0.35 & 3.63 & 7 & 12 & 940 \\
\hline $\mathrm{Y} 9$ & 1200 & 0.20 & 3.63 & 70 & 500 & 900 \\
\hline $\mathrm{Y} 9$ & 1200 & 0.35 & 3.63 & 45 & 425 & 850 \\
\hline
\end{tabular}

Table 4. Activation energy for static recrystallisation of the steels.

\begin{tabular}{|c|c|c|c|}
\hline Steel & Q (J) & Q' $^{\prime}(\mathrm{J})$ & $\Delta Q(\mathrm{~J})$ \\
\hline X3 & 215,000 & 510,000 & 295,000 \\
\hline Y9 & 190,000 & 425,000 & 235,000 \\
\hline Y7 & 185,000 & 235,000 & 50,000 \\
\hline
\end{tabular}


Table 5. Pinning forces exerted by AIN and fine VCN particles for steel Y9.

\begin{tabular}{|c|c|c|c|c|c|c|}
\hline & Temp. $\left({ }^{\circ} \mathrm{C}\right)$ & $\begin{array}{c}\text { Particle } \\
\text { radius } \\
(\mathrm{nm})\end{array}$ & $\begin{array}{c}\text { Precipitated } \\
\text { volume }\end{array}$ & $\begin{array}{c}\text { Gladman } \\
3 \gamma \mathrm{f} / 2 \mathrm{r} \\
\left(\mathrm{MN} / \mathrm{m}^{2}\right)\end{array}$ & $\begin{array}{c}\text { Rigid } \\
\text { boundary } \\
\text { model } \\
6 \gamma \mathrm{f} / \pi \mathrm{r} \\
\left(\mathrm{MN} / \mathrm{m}^{2}\right)\end{array}$ & $\begin{array}{c}\text { Flexible } \\
\text { boundary } \\
\text { model } \\
3 \gamma \mathrm{f}^{2 / 3} / \pi \mathrm{r} \\
\left(\mathrm{MN} / \mathrm{m}^{2}\right)\end{array}$ \\
\hline VCN & 800 & 11.2 & $6 \times 10^{-4}$ & 0.0642 & 0.0819 & 0.4855 \\
\hline AlN & 800 & 86.2 & $6 \times 10^{-4}$ & 0.0083 & 0.0106 & 0.0631 \\
\hline
\end{tabular}




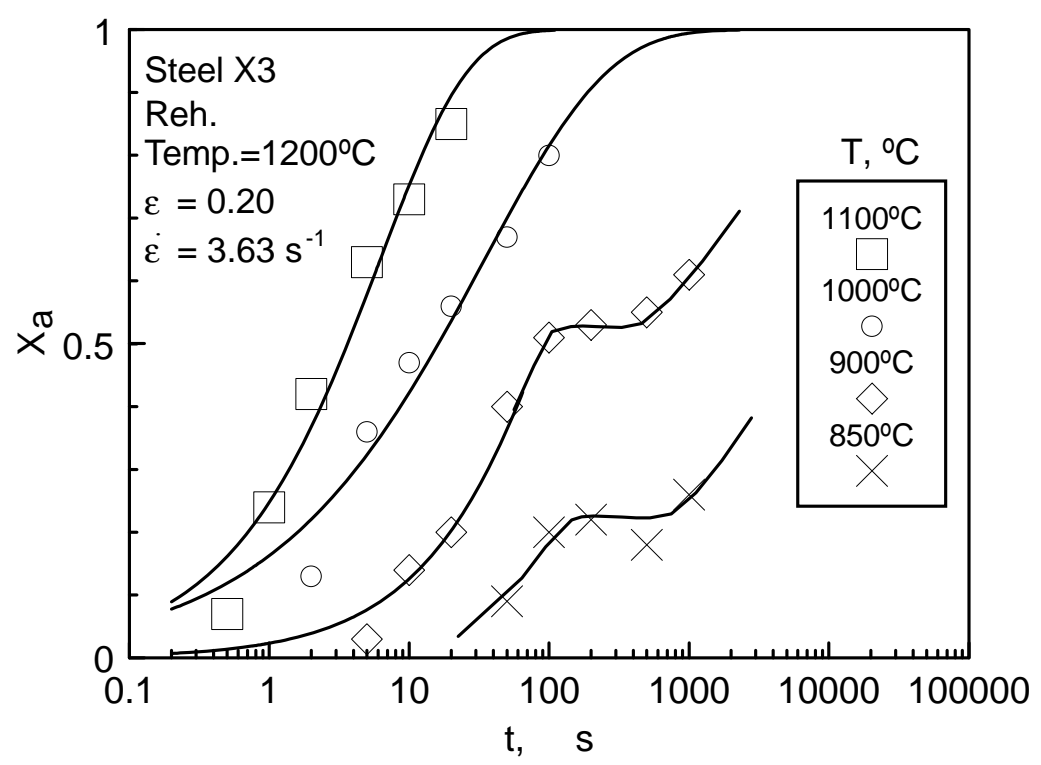

Fig. 1. Variation in the recrystallized fraction $\left(\mathrm{X}_{\mathrm{a}}\right)$ with the time $(\mathrm{t})$ for steel $\mathrm{X} 3$ and strain of 0.20 .

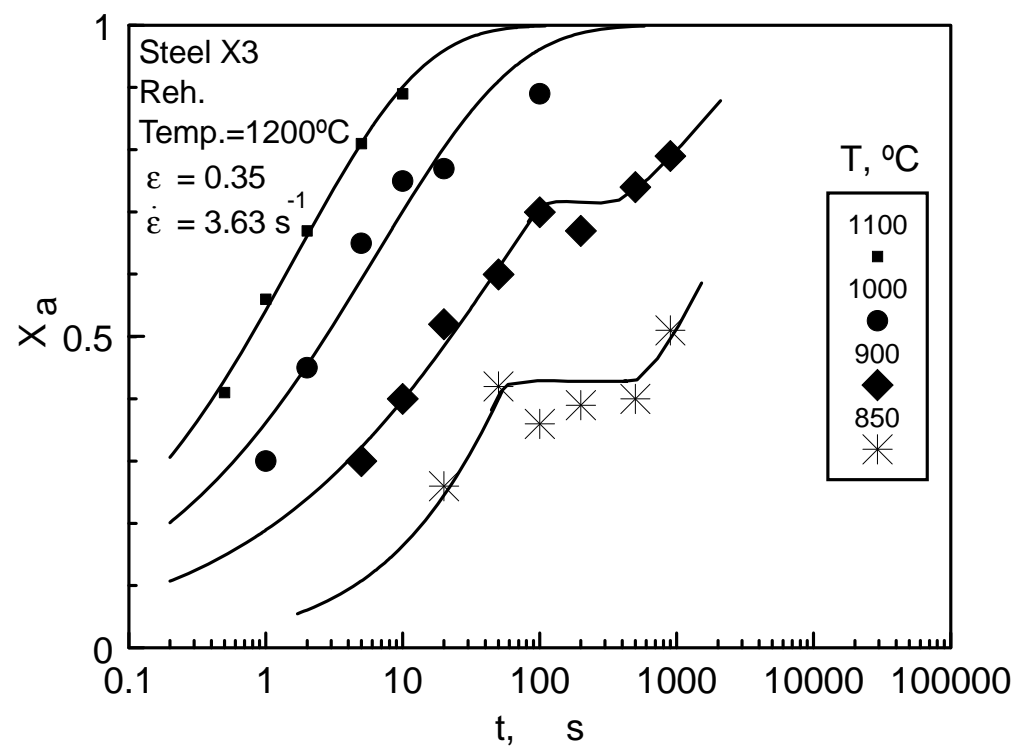

Fig. 2. Variation in the recrystallized fraction $\left(\mathrm{X}_{\mathrm{a}}\right)$ with the time (t) for steel $\mathrm{X} 3$ and strain of 0.35 . 


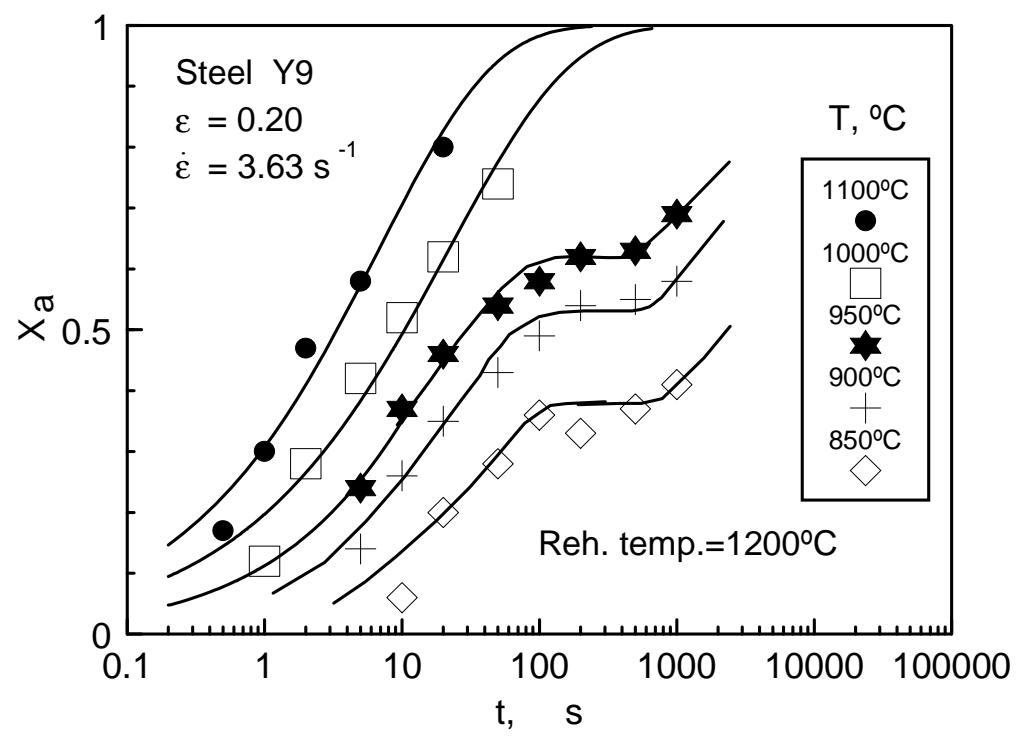

Fig. 3. Variation in the recrystallized fraction $\left(\mathrm{X}_{\mathrm{a}}\right)$ with the time $(\mathrm{t})$ for steel $\mathrm{Y} 9$ and strain of 0.20 .

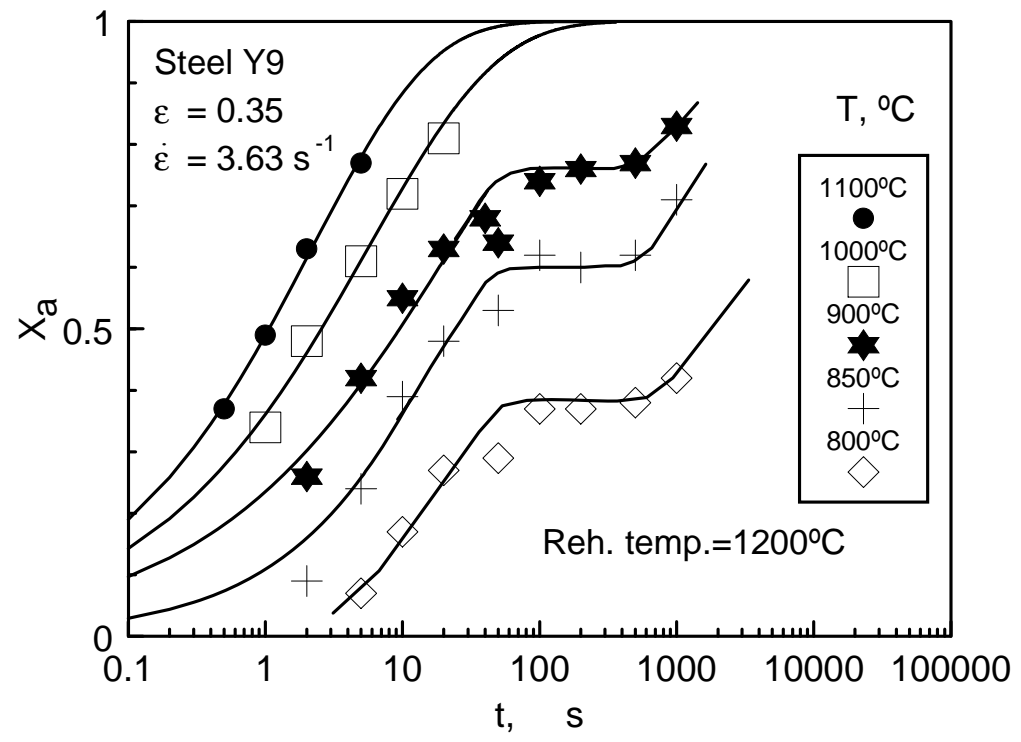

Fig. 4. Variation in the recrystallized fraction $\left(\mathrm{X}_{\mathrm{a}}\right)$ with the time $(\mathrm{t})$ for steel $\mathrm{Y} 9$ and strain of 0.35 . 


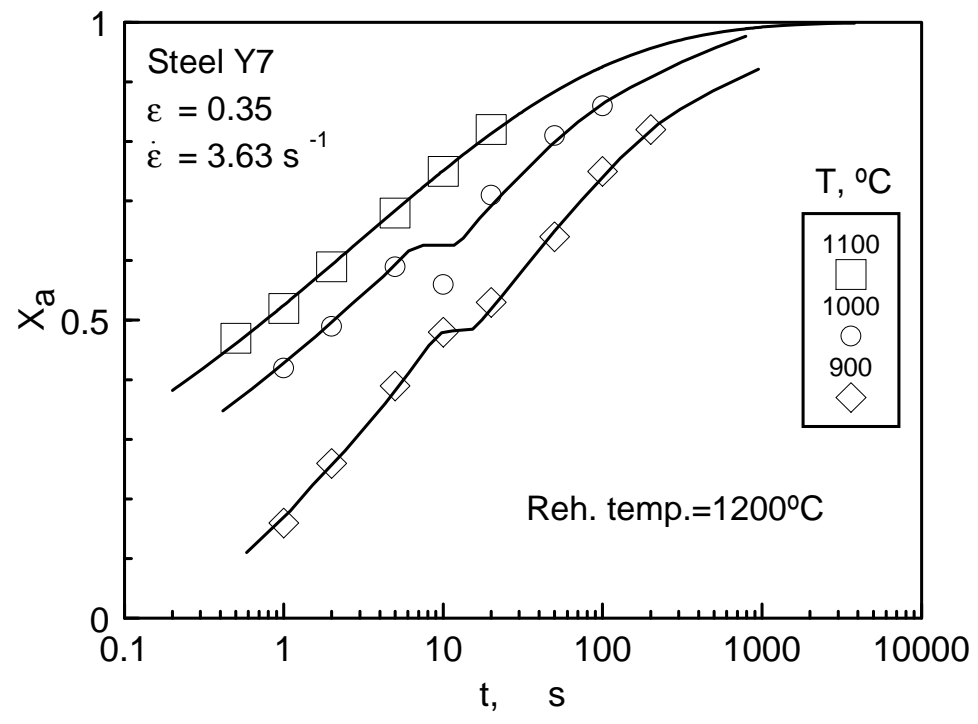

Fig. 5. Variation in the recrystallized fraction $\left(\mathrm{X}_{\mathrm{a}}\right)$ with the time $(\mathrm{t})$ for steel $\mathrm{Y} 7$ and strain of 0.35 .

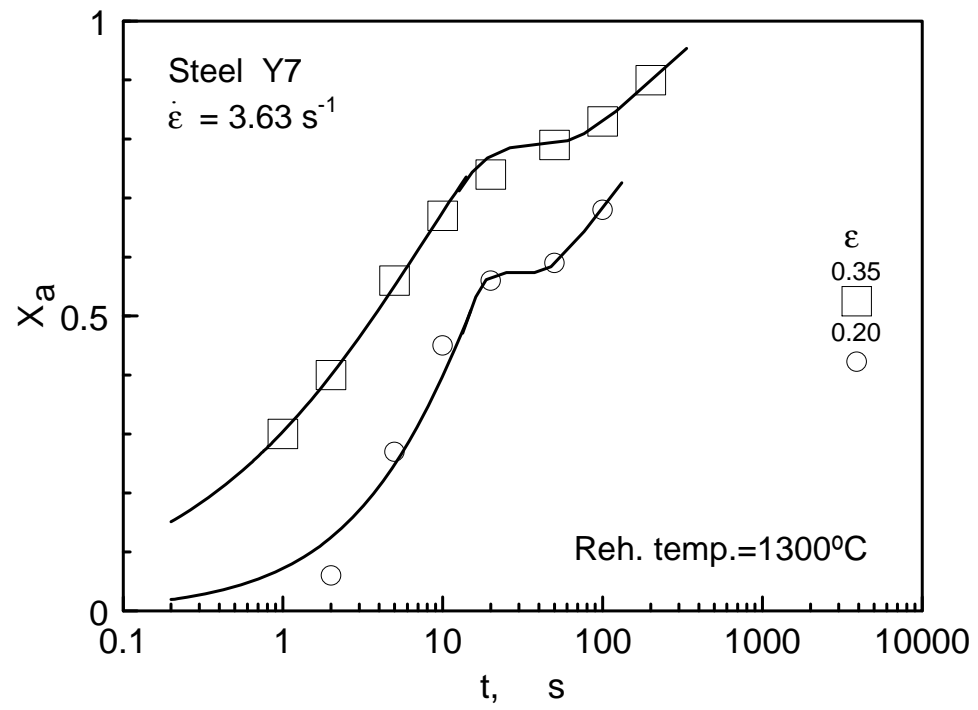

Fig. 6. Variation in the recrystallized fraction $\left(\mathrm{X}_{\mathrm{a}}\right)$ with the time (t) for steel $\mathrm{Y}$ 7. Reheating Temperature $=1300^{\circ} \mathrm{C}$; Deformation temperature $=1000^{\circ} \mathrm{C}$. Strains of 0.20 and 0.35 . 


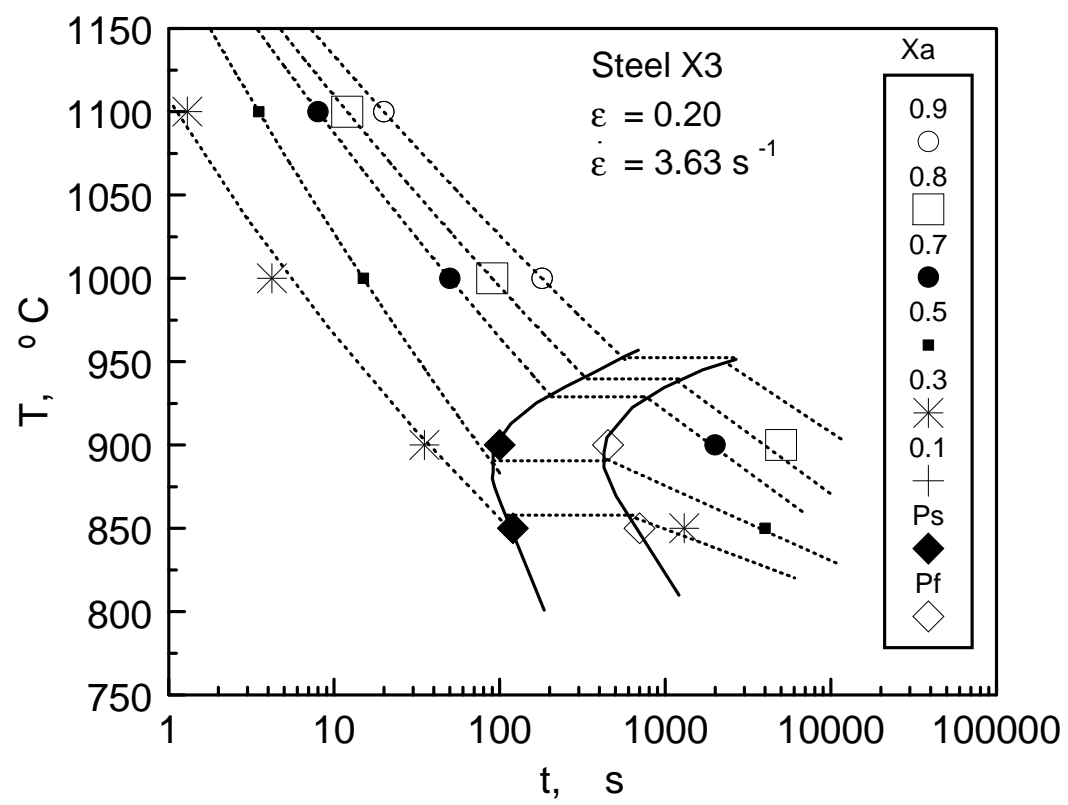

Fig. 7. RPTT diagram for steel X3. $\varepsilon=0.20$.

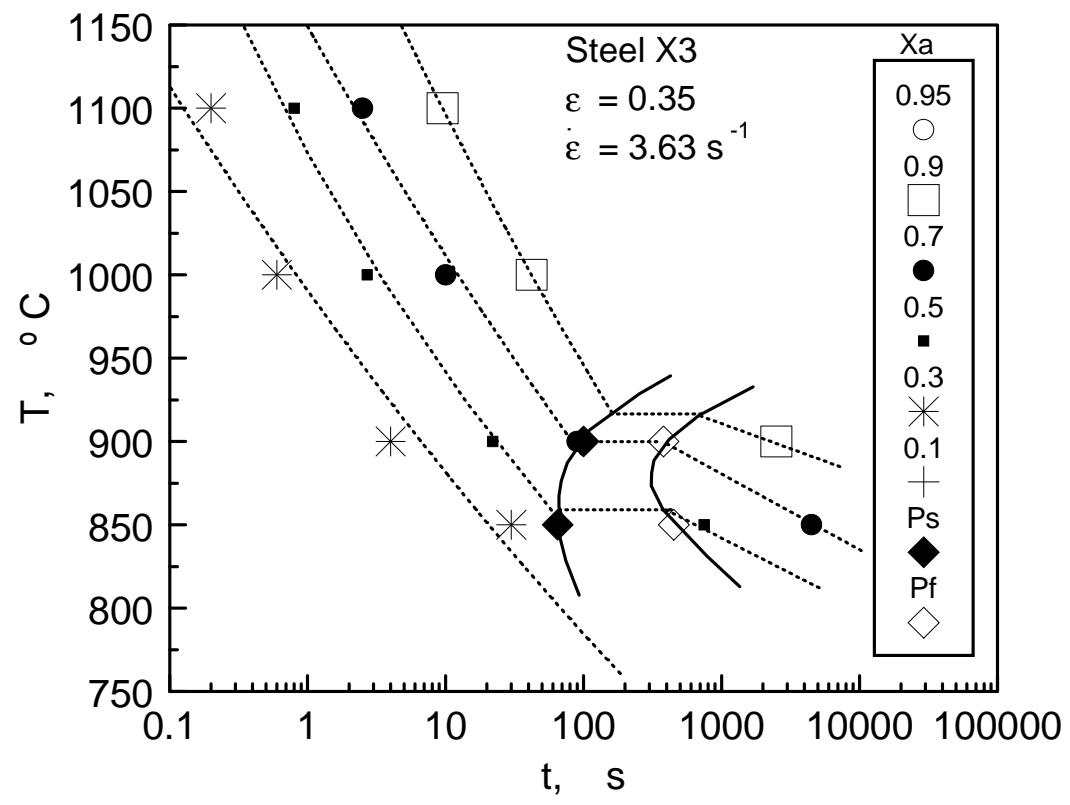

Fig. 8. RPTT diagram for steel X3. $\varepsilon=0.35$. 


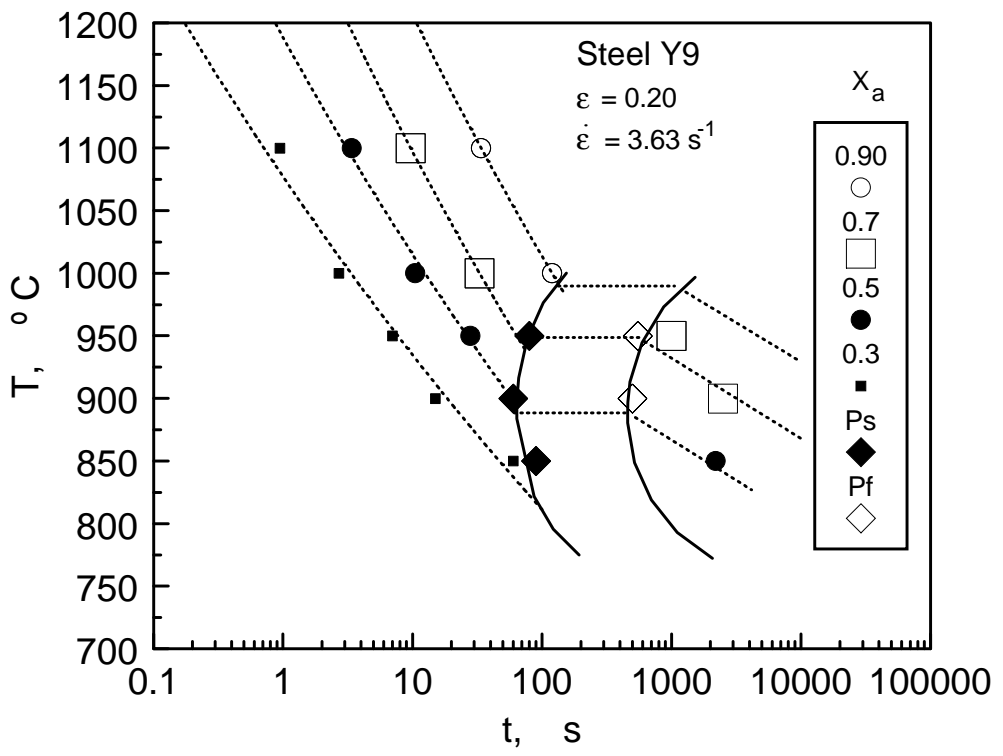

Fig. 9. RPTT diagram for steel Y9. $\varepsilon=0.20$.

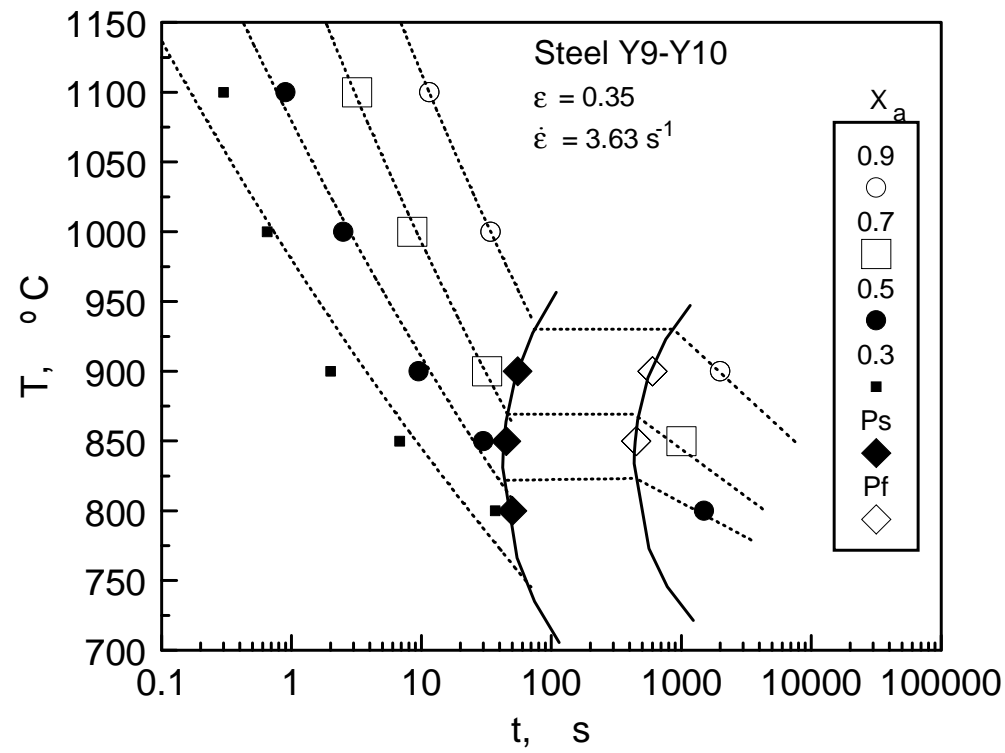

Fig. 10. RPTT diagram for steel Y9. $\varepsilon=0.35$. 


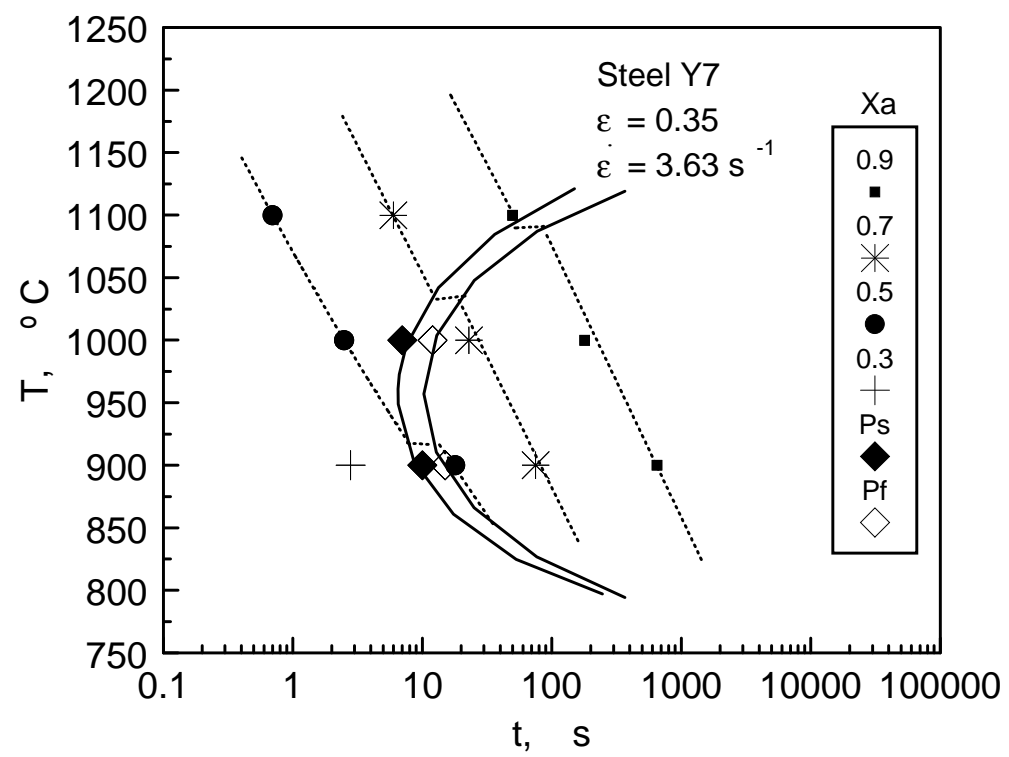

Fig. 11. RPTT diagram for steel Y7. $\varepsilon=0.35$.

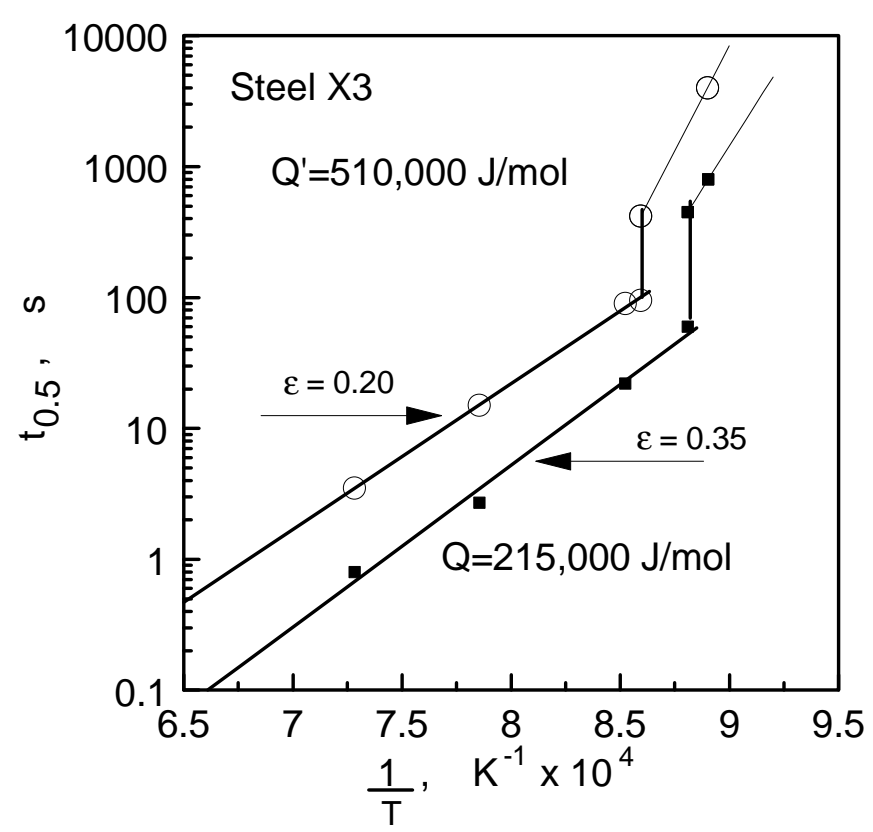

Fig. 12. Plot of t0.5 against the reciprocal of the absolute temperature. Steel X3. 


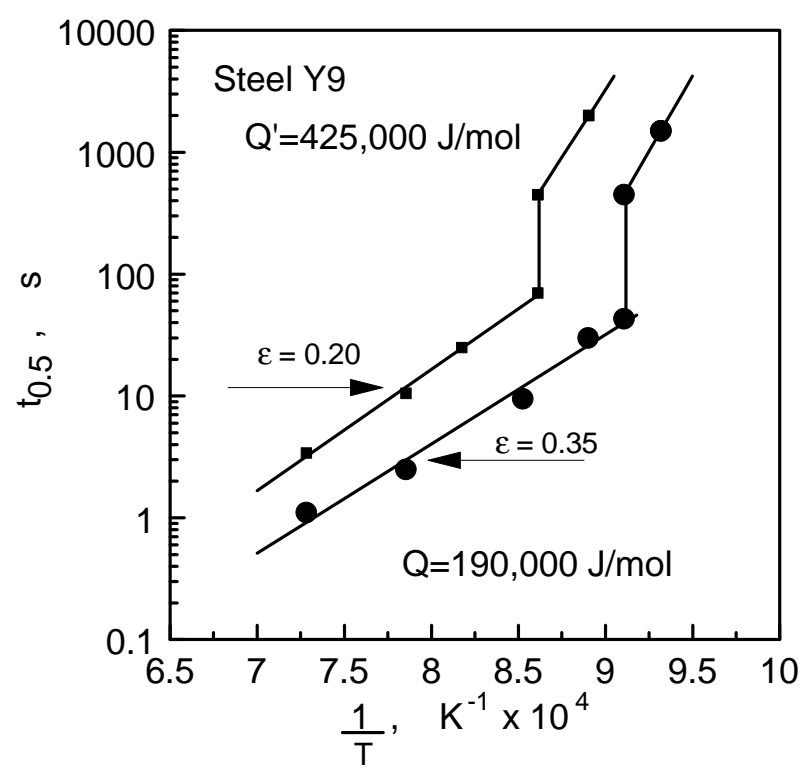

Fig. 13. Plot of t0.5 against the reciprocal of the absolute temperature. Steel Y9.

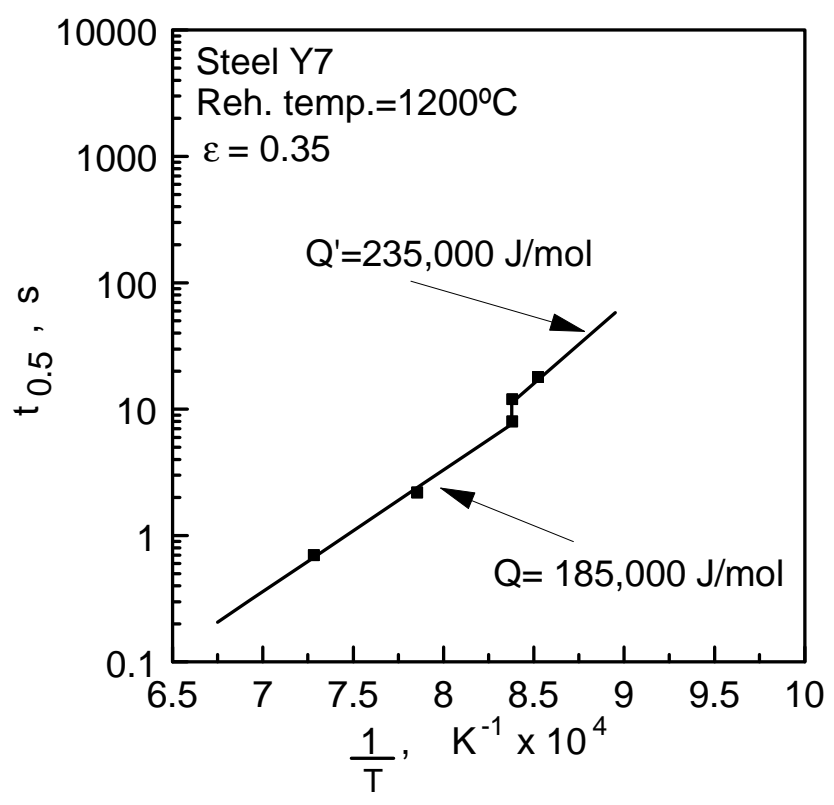

Fig. 14. Plot of t0.5 against the reciprocal of the absolute temperature. Steel Y7. 


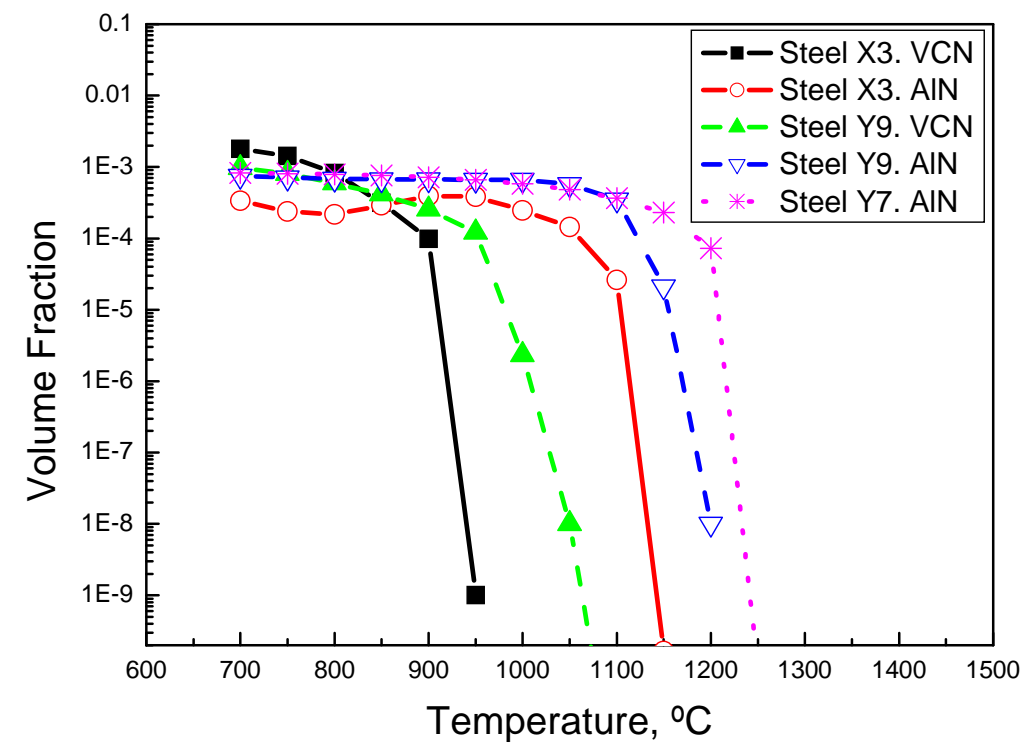

Fig. 15. Prediction of precipitation of $\mathrm{VCN}$ in steels $\mathrm{X} 3, \mathrm{Y} 9$ and $\mathrm{Y} 7$ according to Hillert and Staffanson's model.

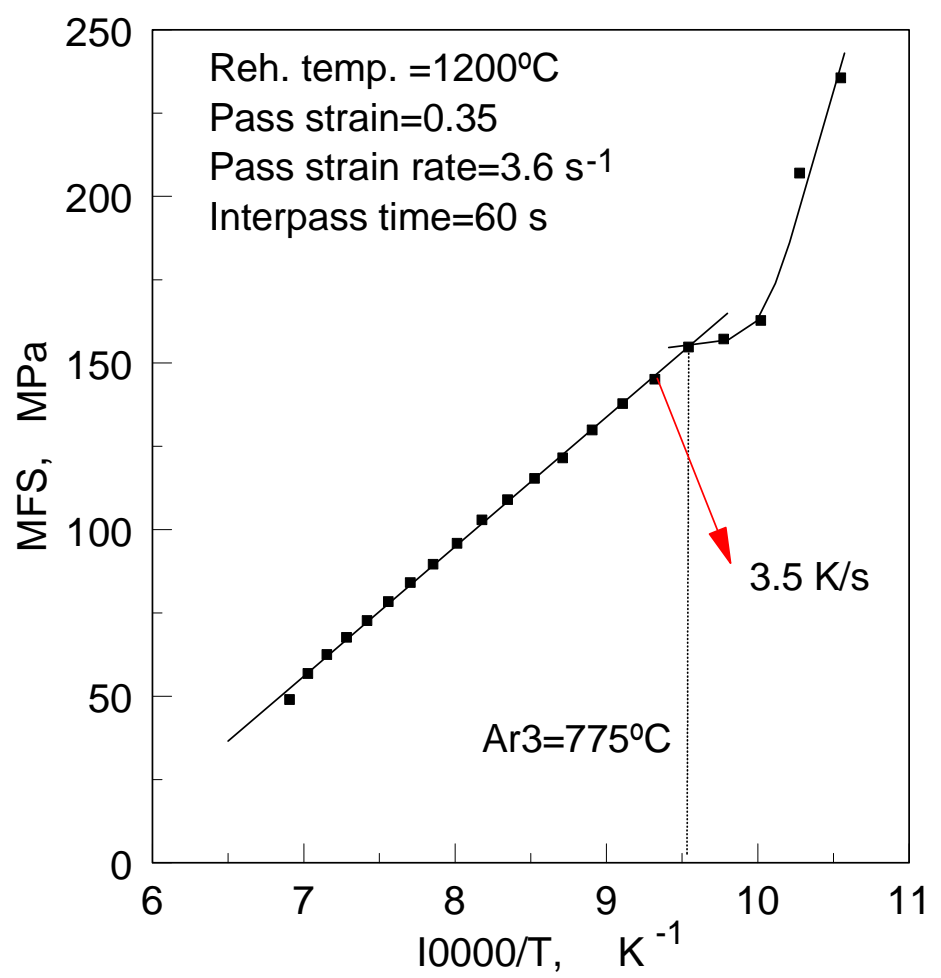

Fig. 16. Mean flow stress (MFS) against reciprocal temperature. Hot rolling simulation by torsion test. Steel Y9. 

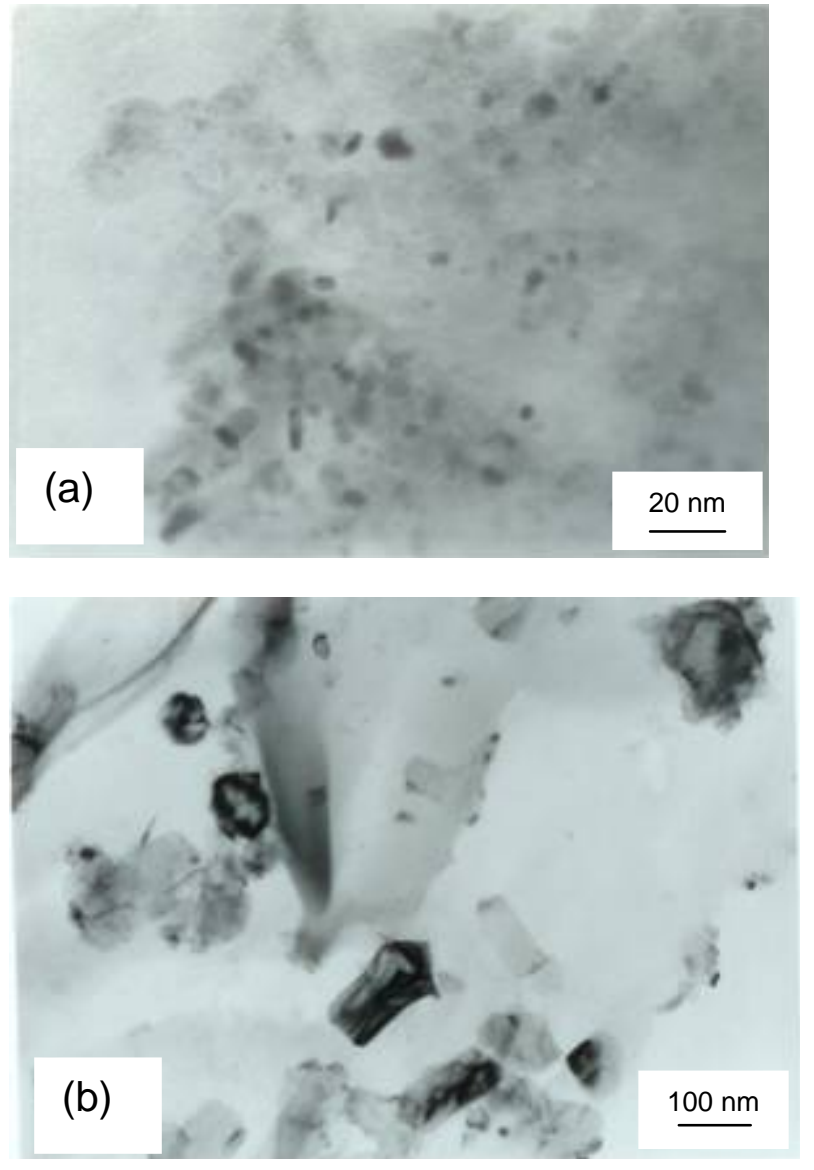

Fig. 17. TEM images of steel Y9 obtained by rolling simulation and cooling by argon from $800^{\circ} \mathrm{C}$. (a) small VN precipitates; (b) big AlN and small VN precipitates. 


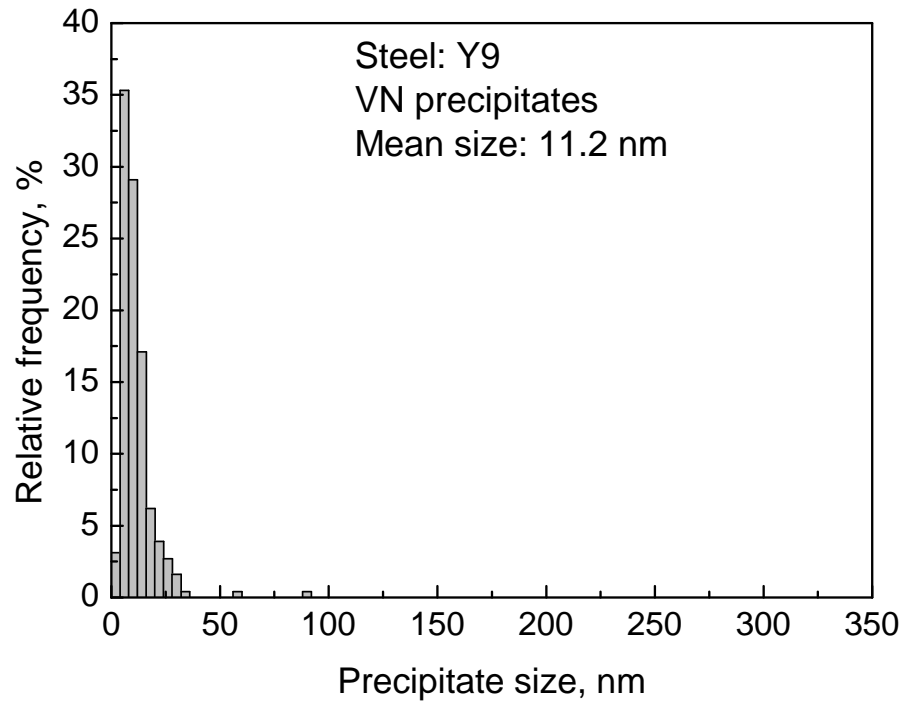

Fig. 18. Relative frequency of VN precipitate size for steel Y9.

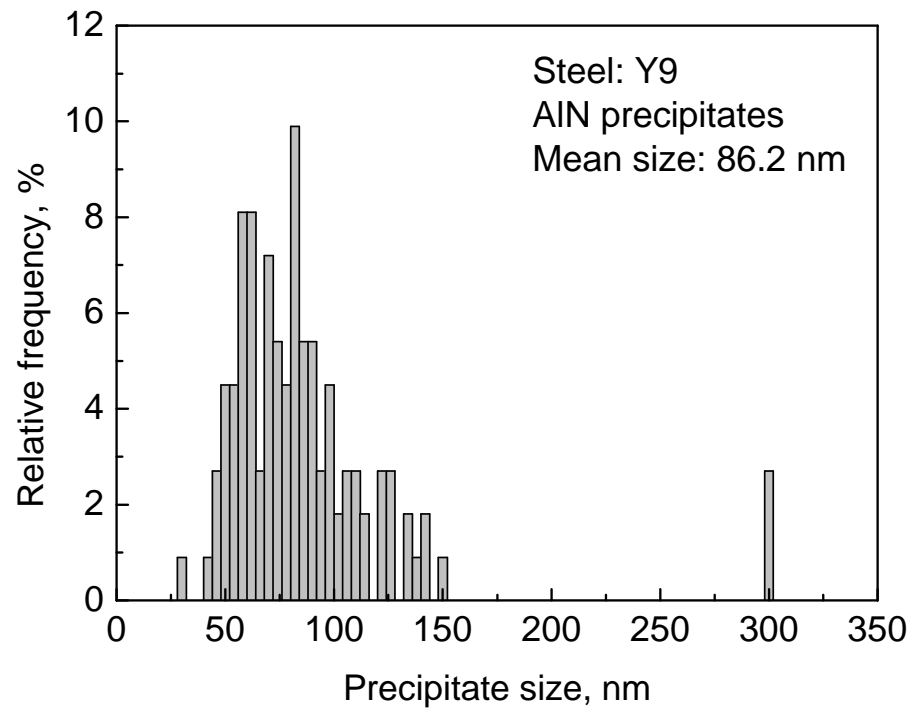

Fig. 19. Relative frequency of AlN precipitate size for steel Y9. 


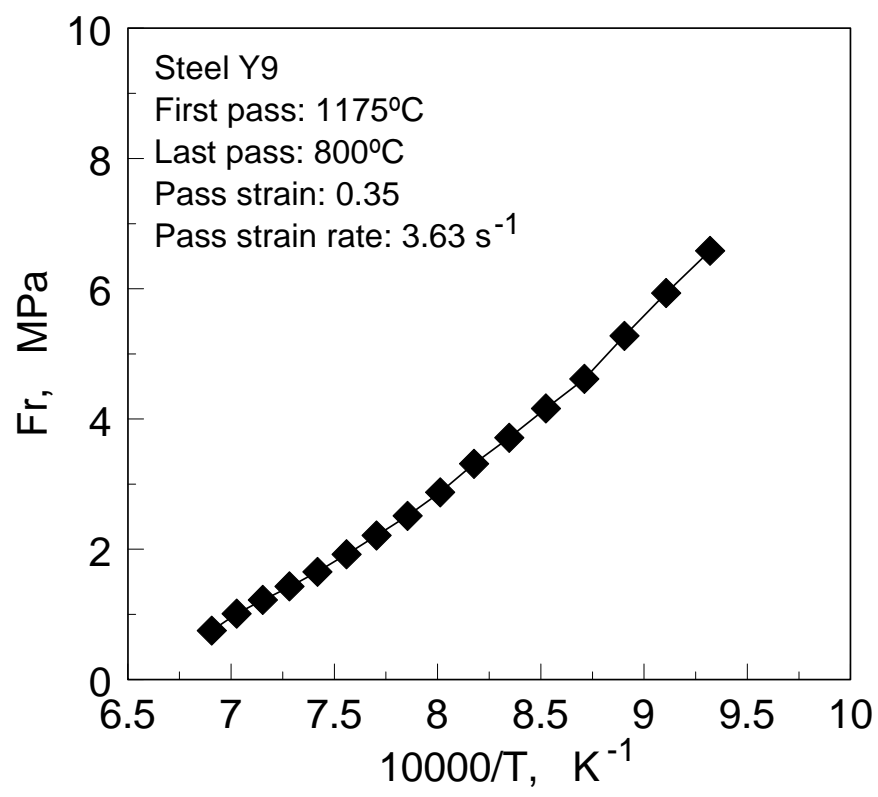

Fig. 20. Driving forces for recrystallisation between passes against reciprocal absolute temperature. Steel Y9.

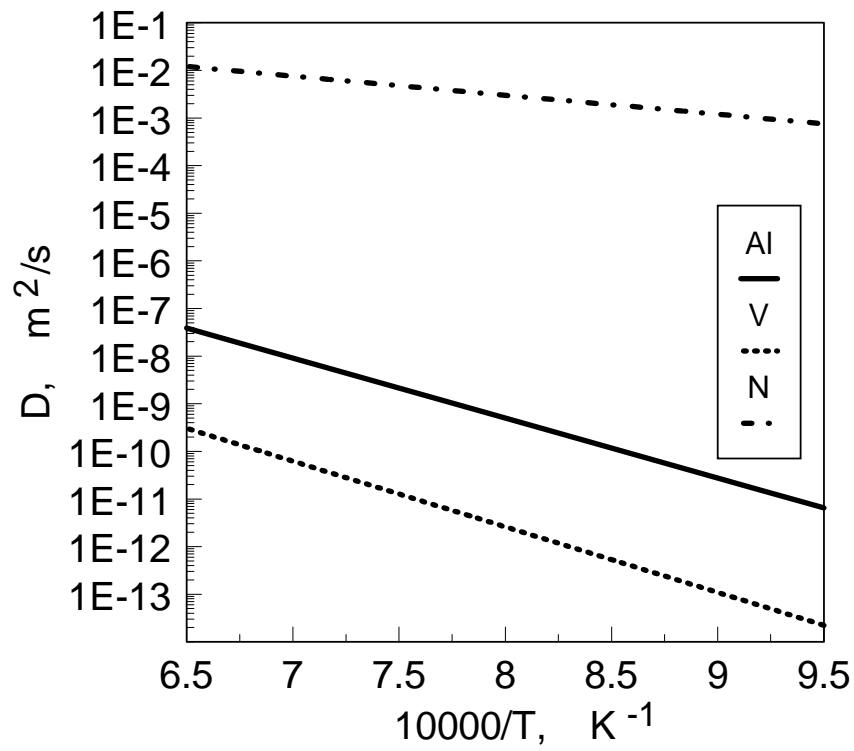

Fig. 21. Difussion coefficient for Al, V and N. 